\title{
Sumatriptan Responsiveness and Clinical, Psychiatric and Psychologic Features in Migraine Patients
}

\author{
S.K. Meckling, W.J. Becker, M.S. Rose, J.T. Dalby
}

\begin{abstract}
Objective: To compare sumatriptan responders and nonresponders in a migraine population with regard to a number of clinical, psychiatric and psychologic features. Methods: Patients were drawn from a referral headache clinic population, and classified as responders or nonresponders. Clinical features were assessed by a written questionnaire. The lifetime prevalence of several psychiatric disorders was determined by the National Institute of Mental Health diagnostic interview schedule and personality factors were measured by the 16 Personality Factors (16PF) Questionnaire. Results: Nonresponders indicated less influence on their migraine by menstrual factors, had a higher lifetime prevalence of generalized anxiety, and showed 16PF scores indicating greater shyness, self-sufficiency and perfectionism. Nonresponders were also more imaginative and less socially outgoing. Conclusion: Although they must be interpreted with caution due to small sample size and the multiple comparisons made, our results indicate that there may be differences between sumatriptan responders and nonresponders with regard to a number of clinical, psychiatric and psychologic factors. These results suggest that biological differences exist between the two patient groups which likely account for both the differences in their responses to sumatriptan and in the clinical features noted above.
\end{abstract}

RÉSUMÉ: La réponse au sumatriptan et les caractéristiques cliniques, psychiatriques et psychologiques des patients migraineux. Objectif: Le but de cette étude était de comparer les répondeurs et les non-répondeurs au sumatriptan d'une population migraineuse quant à certaines caractéristiques cliniques, psychiatriques et psychologiques. Méthodes: Les patients ont été tirés d'une population de patients référés à une clinique de céphalée et classifiés comme répondeurs ou non-répondeurs. Les caractéristiques cliniques ont été évaluées au moyen d'un questionnaire écrit. La prévalence à vie de plusieurs maladies psychiatriques a été déterminée par la cédule d'entrevue diagnostique du National Institute of Mental Health et des facteurs de la personnalité ont été mesurés par le 16 Personality Factors (16PF) Questionnaire. Résultats: Les non-répondeurs ont indiqué que les facteurs menstruels avaient moins d'influence sur leur migraine, avaient une prévalence à vie plus élevée d'anxiété généralisée et avaient des scores au 16PF indiquant une plus grande timidité, un niveau plus élevé d'autonomie et de perfectionnisme. Les non-répondeurs étaient également plus imaginatifs et moins sociables. Conclusions: Bien que nos résultats doivent être interprétés avec prudence à cause de la petite taille de l'échantillon et des comparaisons multiples effectuées, ils indiquent qu'il pourrait exister des différences entre les répondeurs au sumatriptan et les non-répondeurs quant à certains facteurs cliniques, psychiatriques et psychologiques. Ces résultats suggèrent qu'il existe entre les deux groupes de patients des différences biologiques qui sont probablement responsables des différences dans la réponse au sumatriptan et dans les caractéristiques mentionnées.

Can. J. Neurol. Sci. 2001; 28: 313-318

The clinical development program for sumatriptan in the late 1980s and early 1990s showed that the triptans were effective drugs for the symptomatic treatment of migraine headache., ${ }^{1,2}$ Subsequent clinical experience confirmed this, as did the later clinical trials with the newer triptans, ${ }^{3-8}$ although other drug classes, e.g. the nonsteroidal anti-inflammatory drugs still have an important role in some migraine patient populations. ${ }^{9}$

These trials and the subsequent clinical use of the triptans raised several important questions. It soon became clear that even though an individual might respond well to a triptan in some headache attacks, for reasons that were not known, not all the patient's migraine attacks necessarily respond to the triptan. ${ }^{10,11}$ Even more important, some patients with otherwise typical migraine headaches meeting the diagnostic criteria of the

From the Department of Clinical Neurosciences (SKM, WJB) and Department of Community Health Sciences (MSR),University of Calgary and the Department of Psychology. Peter Lougheed Centre, Calgary Regional Health Authority (JTD), Calgary, AB Canada.

ReCEIVED JANUARY 2, 2001. ACCEPTEDIN FinALFORM June 27, 2001 Reprint requests to: W.J. Becker, Foothills Hospital, 12th Floor, Neurology, 1403 29th Street NW, Calgary, Alberta T2N 2T9 Canada 
International Headache Society ${ }^{12}$ did not seem to respond to the triptans at all, or at least not enough to receive a significant treatment benefit. In one study involving 100 consecutive patients seen in a headache clinic, $9 \%$ of patients failed to respond at all to subcutaneous sumatriptan. ${ }^{13}$ As migraine headache response rates are higher with subcutaneous sumatriptan as compared to the oral or nasal forms, ${ }^{14}$ it seems clear that some patients with migraine simply do not respond to the triptans.

The factors associated with nonresponse of migraine patients to the triptans remain to be identified. Our hypothesis was that, although they meet diagnostic criteria for migraine, patients who do not respond to the triptans are biologically different from those who do. These biological differences might result in differences in the clinical features of the headache as well as in the psychiatric and psychologic profile of these patients. While recognising that such differences might be subtle, the objective of our study was to determine if differences could be found.

\section{MeTHODS}

Patients with a diagnosis of migraine with or without aura were identified from the University of Calgary Headache Research Clinic computer database in 1996, and requested by telephone to participate in this study. These diagnoses in the clinic were made according to International Headache Society criteria. ${ }^{12}$ Patients who had been given in addition a diagnosis of transformed migraine ${ }^{15}$ by the clinic physician were not contacted.

The database was searched starting from the date of the study and going back in time. An attempt was made to contact all eligible patients living in the Calgary region. Because responders outnumbered nonresponders, eventually only nonresponders were recruited as the database was searched further back in time in order to keep the groups from becoming too unequal in size. After the recruitment of 25 nonresponders, recruitment was stopped due to limitations of time and resources. As a result of this process, 74 eligible patients who agreed to participate made up the study population.

Clinical records were reviewed to determine whether the patient was responsive to sumatriptan or not. In addition, the study questionnaire which was completed by all patients obtained detailed information on the patient's past experience with sumatriptan and other migraine medications. Most patients had tried sumatriptan multiple times in the past, either while under our care or under the care of other physicians. Patients who were nonresponsive to oral sumatriptan but who had not tried subcutaneous sumatriptan at least twice were asked to treat two headaches during our study with subcutaneous sumatriptan (6 mg) which was provided so that they could be more securely classified as nonresponders. Six of the 25 sumatriptan nonresponders did not try subcutaneous sumatriptan after recruitment into the study for various reasons including needlephobia. One had had significant worsening of headache after a single dose of subcutaneous sumatriptan in the past, and did not wish to take a further dose.

Patients who rarely or never responded to sumatriptan were considered nonresponders. Patients who had headache relief from sumatriptan but who had significant side effects and/or headache recurrence were still considered responders. Because our objective was to compare approximately similar sized groups of responders and nonresponders, the database was searched more extensively to identify nonresponders, as they were less common in our clinic population. The size of our patient groups do not, therefore, reflect the relative frequencies of responders and nonresponders in our clinic population.

After informed consent, all participants completed a detailed questionnaire which obtained information on various demographic factors and on clinical features of their headaches (74 patients).

In addition, 69 patients completed both the National Institute of Mental Health, Diagnostic Interview Schedule (DIS) (revised to cover DSM-III-R Disorders) and the 16 Personality Factor Questionnaire (16PF - 5th Edition).

The DIS determines the patient's lifetime history of psychiatric disorders. The DIS was administered by a trained interviewer. Only that portion relevant to diagnoses of interest to us (generalized anxiety, anxiety, panic disorder, phobias, major depression, dysthymia, obsessive compulsive disorder, nicotine abuse, alcohol abuse, nonprescription drug abuse, and prescription drug abuse) was administered.

The self-administered $16 \mathrm{PF}$ questionnaire was used to delineate the major normal personality traits of the patients in order to form a broad picture of each patient's personality.

\section{Statistical analysis}

In all analyses, the dependent variable was the binary variable indicating group membership, i.e. sumatriptan responder or nonresponder. A graphical and descriptive analysis was done examining the difference between the responder and nonresponder groups in each of the factors analyzed individually.

Categorical variables such as sex were cross-tabulated with the dependent variable and significant differences detected by means of the Fisher Exact Test. Differences in the continuous variables were examined graphically using box plots and tested using a T-test. For analysis of the $16 \mathrm{PF}$ results, a two-tailed T-test was used to compare the two groups.

The issue of our relatively small sample size and the power of our study needs to be addressed. For categorical variables, e.g. the presence or absence of a clinical feature such as a lifetime history of generalised anxiety, a two-sample binary power calculation shows that a sample size of 30 for each group (which would approximate the power of our groups) would have a power of 0.6 to detect a difference at the $\mathrm{p}<0.05$ level if $25 \%$ of patients in one group had the variable as opposed to $5 \%$ in the other group. We could therefore have missed some differences of that magnitude between our groups because of our small sample size (25 in one group, 49 in the other). Asample size of 49 in each group would have been necessary for a power of 0.8 to detect such differences at the $\mathrm{p}<0.05$ level. Similarly, our study could have missed some differences between our two groups in the personality factors measured on the $16 \mathrm{PF}$ because of low power.

\section{RESUltS}

Sixty-four (64) of the 74 subjects who agreed to participate were female and ten were male. Forty-nine (49) patients were classified as sumatriptan responders (44 women and five men), and 25 patients were nonresponders (20 women and five men). Although our patients were drawn from a headache referral clinic 
and no doubt represent the more severe end of the migraine headache spectrum, approximately $60 \%$ in each group reported five or fewer migraine headaches per month. On the other hand, even though patients who had been given a diagnosis of transformed migraine on their clinic visit were not included in the study, approximately $20 \%$ of patients in each group indicated they had more than 15 days with headache each month on the study questionnaire, and would qualify for a diagnosis of transformed migraine as described by Silberstein et $\mathrm{al}^{15}$ at the time of the study. Some of these patients overused a variety of symptomatic medications including analgesics. Sumatriptan responders and nonresponders did not differ significantly on multiple factors including sex, education level obtained, and body mass index. The responder group tended to be slightly older ( $\mathrm{p}=0.03)$, (Tables 1 and 2$)$.

There were no differences between the two groups in many of the multiple clinical features examined including age at migraine onset, headache frequency, usual headache duration, unilateral versus bilateral headaches, and the percentage of patients with associated symptoms like vomiting, sonophobia, and photophobia. Patients in both groups could identify a mean of approximately six migraine triggers. The only difference between the two groups in terms of clinical features was that only $15 \%$ of patients in the sumatriptan nonresponder group stated that greater than $25 \%$ of their headaches were menstrually related, as compared to $56 \%$ of patients in the responder group $(\mathrm{p}=0.003)$, (Tables 1 and 2).

The lifetime occurrence of many psychiatric disorders in the two groups as measured by the DIS was also similar (Table 3). These included the occurrence of anxiety, panic, phobias, major depression, dysthymia, obsessive compulsive disorder, and various categories of drug abuse. The only exception was a diagnosis of generalized anxiety, which had occurred during their lifetime in $22.7 \%$ of sumatriptan nonresponders and only in $4.3 \%$ of sumatriptan responders $(\mathrm{p}=0.030)$.

Four of the sixteen primary personality traits as measured by the 16PF were statistically significantly different between the two patient groups $(\mathrm{p}<0.05)$ (Table 4$)$. The scales of the $16 \mathrm{PF}$ are designed in terms of dichotomies, with high scores reflecting one end of the dichotomy, and low scores the other. The four dichotomies where the two groups showed statistically significant differences were the shy/bold, the practical/imaginative, the group oriented/self-sufficient, and undisciplined/perfectionistic dichotomies. The scores indicated that the nonresponders as a group tended to be more shy, less group oriented, more perfectionistic, and more imaginative. These results could be summarised by describing sumatriptan nonresponders as individuals who, compared to responders, are more timid and shy, more self-sufficient and less group oriented, more perfectionistic, organised, and self-disciplined, and more imaginative and unconventional. Nonresponders were also less socially outgoing. This was particularly evident on the extroversion second order factor which is a compilation of several primary factors.

\section{DISCUSSION}

We separated our migraine patients into two groups: sumatriptan responders and nonresponders. Other triptans were not yet available in Canada at the time of the study. One could
Table 1: Patient Demographics and Migraine Clinical Features

\begin{tabular}{lccr}
\hline & $\begin{array}{c}\text { Sumatriptan } \\
\text { Nonresponders } \\
(\mathbf{n = 2 5})\end{array}$ & $\begin{array}{c}\text { Sumatriptan } \\
\text { Responders } \\
(\mathbf{n = 4 9 )}\end{array}$ & $\mathbf{p}$ \\
& $37.6(11.2)^{*}$ & $42.8(8.7)$ & 0.03 \\
Age & $28.1(21.5)$ & $27.4(16.7)$ & 0.879 \\
Body Mass Index & $18.6(11.6)$ & $19.5(10.0)$ & 0.733 \\
Age at migraine onset (years) & $7.8(7.9)$ & $7.4(7.3)$ & 0.844 \\
Headache frequency (per month) & $31.8(27.0)$ & $40.4(29.6)$ & 0.218 \\
Usual headache duration (hours) & $5.9(3.3)$ & $5.8(3.2)$ & 0.878 \\
Number of identified triggers & & &
\end{tabular}

* Mean with standard deviation

Table 2: Patient Demographics and Migraine Clinical Features (\% of Patients)

\begin{tabular}{lccc}
\hline & $\begin{array}{c}\text { Sumatriptan } \\
\text { Nonresponders } \\
(\mathbf{n = 2 5})\end{array}$ & $\begin{array}{c}\text { Sumatriptan } \\
\text { Responders } \\
(\mathbf{n = 4 9 )}\end{array}$ & $\mathbf{p}$ \\
$\quad 20$ & 10.2 & 0.290 \\
Male sex & 28 & 22 & 0.400 \\
$\quad$ No formal education beyond & 32 & 41 & 0.316 \\
$\quad$ high school & 60 & 71.4 & 0.432 \\
$\quad$ University graduate & 15 & 55.8 & 0.003 \\
Headache mainly unilateral & & & \\
>25\% of headaches related to & & 77.6 & 1.000 \\
$\quad$ menstruation (females only) & 10 & 81.6 & 0.559 \\
$\quad$ Vomiting with migraine & 76 & 89.8 & 0.657 \\
$\quad$ (at least occasionally) & 96 & & \\
Sonophobia & & & \\
Phonophobia & & & \\
&
\end{tabular}

Table 3: Lifetime Prevalence of Psychiatric Disorders (\%)

\begin{tabular}{lccc}
\hline & $\begin{array}{c}\text { Sumatriptan } \\
\text { Nonresponders } \\
(\mathbf{n = 2 2})\end{array}$ & $\begin{array}{c}\text { Sumatriptan } \\
\text { Responders } \\
(\mathbf{n = 4 7 )}\end{array}$ & $\mathbf{p}$ \\
Generalized anxiety & 22.7 & 4.3 & 0.030 \\
Anxiety & 45.5 & 36.2 & 0.597 \\
Panic & 13.6 & 6.4 & 0.375 \\
Phobia & 40.9 & 34.0 & 0.601 \\
Major depression & 36.4 & 25.5 & 0.401 \\
Dysthymia & 9.1 & 10.6 & 1.000 \\
Obsessive compulsive disorder & 2.1 & 4.6 & 0.539 \\
Nicotine abuse & 27.3 & 21.3 & 0.760 \\
Alcohol abuse & 18.2 & 14.9 & 0.734 \\
Nonprescription drug abuse & 9.1 & 4.3 & 0.587 \\
Prescription drug abuse & 9.1 & 2.1 & 0.237 \\
Any substance abuse* & 45.5 & 34.0 & 0.429 \\
& & & \\
\hline
\end{tabular}

* Some patients abused more than one substance 
Table 4: 16 Personality Factors Questionnaire Results

\begin{tabular}{lrc}
\hline $\begin{array}{l}\text { Primary Factors } \\
\text { Low/High Score descriptions }\end{array}$ & $\begin{array}{c}\text { Sumatriptan } \\
\text { Nonresponders } \\
(\mathbf{n = 2 2}) \\
\text { Mean (SD) }\end{array}$ & $\begin{array}{c}\text { Sumatriptan } \\
\text { Responders } \\
(\mathbf{n}=47) \\
\text { Meaw (SD) }\end{array}$ \\
& $\begin{array}{c}\text { Raw Scores } \\
\text { Raw Scores }\end{array}$ \\
A. Reserved/Outgoing & $9.5(4.2)$ & $15.4(4.8)$ \\
B. Concrete/Abstract thinking & $9.4(3.1)$ \\
C. Affected by feelings/emotionally stable & $11.0(5.9)$ & $13.0(5.1)$ \\
E. Submissive/Dominant & $12.5(4.8)$ & $11.5(4.5)$ \\
F. Sober/Enthusiastic & $10.1(4.2)$ & $10.5(3.8)$ \\
G. Expedient/Conscientious & $13.4(3.9)$ & $14.6(4.1)$ \\
H. Shy/Bold & $9.5(5.2)$ & $10.9(6.5)^{*}$ \\
I. Tough/Tender-minded & $15.5(5.3)$ & $16.3(4.0)$ \\
L. Trusting/Suspicious & $9.4(4.8)$ & $8.6(4.5)$ \\
M. Practical/Imaginative & $8.8(4.6)$ & $6.3(5.2)^{*}$ \\
N. Forthright/Shrewd & $12.2(4.8)$ & $10.2(5.2)$ \\
O. Self-assured/Apprehensive & $13.2(6.0)$ & $12.9(5.2)$ \\
Q1. Conservative/Experimenting & $18.3(4.9)$ & $17.0(5.5)$ \\
Q2. Group-oriented/Self-sufficient & $10.6(4.8)$ & $8.2(5.3)^{*}$ \\
Q3. Undisciplined/Perfectionistic & $12.5(5.0)$ & $10.7(4.9)^{*}$ \\
Q4. Relaxed/Tense & $12.0(4.7)$ & $10.6(4.7)$
\end{tabular}

Second Order Factors (Sten)

$\begin{array}{lll}\text { Extroversion } & 4.9(1.8) & 5.8(1.8)^{*} \\ \text { Anxiety } & 5.9(2.2) & 5.2(2.1) \\ \text { Tough poise } & 4.7(2.2) & 5.1(1.9) \\ \text { Independence } & 5.5(1.69) & 4.9(2.0) \\ \text { Superego/Control } & 5.3(1.5) & 5.6(1.6)\end{array}$

* significant difference at .05 probability level (two-tailed)

question whether or not triptan unresponsive migraine patients truly exist. Some patients who do not respond to sumatriptan may respond to other triptans. ${ }^{16}$ There is also the issue of whether some triptan "unresponsive" patients might respond if the triptan dose was increased beyond the usual clinical dosage levels. Although the percentage of patients who respond to sumatriptan seems to increase very little if dosages are increased beyond 100 mg up to $300 \mathrm{mg},{ }^{17}$ some other triptans appear to have a greater dose response relationship. With rizatriptan, $67 \%$ of patients in one study responded to a $40 \mathrm{mg}$ dose, as compared to only $52 \%$ who responded to a $10 \mathrm{mg}$ dose. ${ }^{18}$ However, we believe it is fair to say that our "sumatriptan unresponsive" patients were at least relatively resistant to the therapeutic effects of sumatriptan, as compared to our sumatriptan responders. Such an interpretation is in agreement with the findings of Sheftell et $\mathrm{al}^{13}$ who found in their clinical practice that $9 \%$ of the first 100 patients for whom they prescribed sumatriptan did not respond to it. Similarly, Visser et $\mathrm{al}^{19}$ found in a large series of migraine patients that migraine attacks hardly ever improved in $9 \%$ of patients with subcutaneous sumatriptan and $18 \%$ of patients with oral sumatriptan. It is recognised that even in patients who respond well to sumatriptan, some migraine attacks still do not respond satisfactorily to the drug. It is unclear why this is the case, but this is presumably due to pharmacokinetics or other factors, rather than the basic biological differences which we hypothesise separate our two patient groups.

Why some migraine patients are sumatriptan resistant is unclear. Differences in the pharmacokinetic and pharmacodynamic profiles of sumatriptan in different patient groups do not seem to account for whether patients are responsive or nonresponsive to sumatriptan. ${ }^{20}$ Investigations up to this point also suggest that known genetic diversity in the $5 \mathrm{HT}_{1 \mathrm{~B}}$ receptor does not predict clinical responsiveness or nonresponsiveness to sumatriptan. $^{21}$ One would expect, however, that some biochemical factor or factors, presumably genetically based, must be responsible for the sumatriptan resistance seen in a minority of patients with migraine. If this is indeed the case, then one might expect significant differences in the clinical features of the migraine attacks in sumatriptan nonresponders versus sumatriptan responders. However, like Visser et $\mathrm{al},{ }^{22}$ we found few clinical differences in the two groups. In our study, clinical features like age at migraine onset, usual headache duration, the presence of various associated migraine symptoms, and most of the other clinical features shown in Tables 1 and 2 were similar in responders and nonresponders. The one exception was that in response to the question "What percentage of your headaches are related to your menstrual cycle?", only $15 \%$ females in the nonresponder group indicated that $>25 \%$ of their headaches were related, as compared to $56 \%$ in the sumatriptan responder group. Because of the multiple comparisons done in our study, it might be argued that this is a chance finding, however, the highly significant $p$ value $(p=0.003)$ makes this unlikely. Visser et al, ${ }^{22}$ in a larger study, apparently did not find differences between responders and nonresponders with regard to menstrual migraine, although they asked the question somewhat differently, and did not ask women to give a percentage estimation of what proportion of their migraine headaches were menstrually related.

In patients with migraine triggered by menstruation, falling estrogen levels are thought to be the main trigger for these attacks, ${ }^{23,24}$ and the same is likely true for headaches occurring at ovulation. Hence, if sumatriptan responders truly do have more menstrual cycle influences on headache occurrence, this could reflect a difference in the biochemical or physiological mechanisms underlying their migraine attacks.

Patients with migraine are known to have a higher prevalence of major depression than individuals without migraine, ${ }^{25,26}$ and a higher prevalence of anxiety disorders, particularly general anxiety (odds ratio 5.3). ${ }^{25}$ In our sample, $36 \%$ of sumatriptan nonresponders had suffered a major depression at some time, versus $26 \%$ of responders, but this difference was not statistically significant. However, generalized anxiety disorder, either current or in remission was present in $23 \%$ of sumatriptan nonresponders as compared to only $4 \%$ of sumatriptan responders $(\mathrm{p}=0.030)$. This higher lifetime prevalence of generalized anxiety in sumatriptan nonresponders versus responders, given our small sample size, requires confirmation. It could reflect underlying biological differences between our two patient groups. One possibility is that some 5HT receptor subtypes, or their related mechanisms which produce migraine relief, are different or less functional in sumatriptan nonresponders as compared to responders. There are precedents for this in other disorders. For example, the normal rise in serum growth hormone seen after administration of sumatriptan, a 
$5 \mathrm{HT}_{\mathrm{ID}}$ receptor mediated function, is blunted in major depression. ${ }^{27}$ Further studies using the DIS ${ }^{28}$ with larger patient numbers are needed to help clarify the relationship between migraine, psychiatric disorders, and sumatriptan responsiveness.

The $16 \mathrm{PF}$ was developed by Cattell to assess 16 personality traits which he considered the building blocks of personality. ${ }^{29,30}$ It is of interest that differences were present at the $p<0.05$ level between our two patient groups for four of the sixteen traits (primary factors). Our two groups were also different for one of the five second-order factors: extroversion. The significance of these findings is not clear. On the one hand, these personality factors are likely under genetic control to some extent, and once again the differences found could be evidence that our sumatriptan nonresponders are biologically different from responders. On the other hand, our nonresponders tended to be less socially affiliative and more perfectionistic than the responders. It is possible that these personality characteristics in themselves could influence drug response.

Our study has several limitations. In general, patients referred to the University of Calgary Headache Research Clinic represent the more severe end of the migraine disorder spectrum. Although not all our patients have seen other specialists before referral to us, many have. This may limit the generalisability of our findings to all patients with migraine. Also, our sample size was not large, and it is possible that some other differences between our two patient groups exist which were not detected by our study. On the other hand, because multiple comparisons were made, it is possible that some of the differences found by us, e.g. in the prevalence of generalised anxiety which had a $p$ value of 0.030 , were due to chance. Our results must, therefore, be interpreted with caution. Our two patient groups also differed slightly with regard to age and the percentages of males and females, but these differences were not large and unlikely to have influenced our findings. The differences in patient numbers in our two patient groups would not be expected to influence the statistical analysis, beyond the reduction in power resulting from the small size of one patient group.

It is also uncertain whether other medications used by our patients may have affected our findings. Although the differences were not statistically significant within the power of our study, substance abuse as measured by the DIS was numerically more common in the nonresponder group (45.5\% of patients) as compared to the responder group (34\%). However, most of this substance abuse related to smoking (27\% of nonresponders, $21 \%$ of responders). Prescription drug abuse had occurred at some time in their lives in $9.1 \%$ of nonresponders and $2.1 \%$ of responders. It is possible that prescription drug abuse may have influenced sumatriptan responsiveness and/or personality profiles in some patients but, given the relatively small number of patients involved (two nonresponders and one responder), is unlikely that prescription drug abuse materially influenced our overall findings.

Our study also cannot determine if some of the differences between the two groups observed by us were the result of the differing responses to sumatriptan between the two groups rather than the result of an underlying biological difference. For example, if a patient with severe migraine did not respond to the best available medication, this could perhaps secondarily give rise to anxiety.
In summary, our data showed differences between patients who did not respond to sumatriptan and those who did in several areas, including the patient's perception of whether their headache occurrence was related to their menstrual cycle, in the lifetime prevalence of generalized anxiety disorder as measured by the DIS, and in the frequency of a number of personality traits. All these findings suggest that sumatriptan nonresponders are biologically different from responders. The nature of the underlying biological factors responsible for these differences and the mechanisms whereby they influence sumatriptan responsiveness are unknown, although one possibility is that these clinical features reflect differences in serotonergic mechanisms between the two groups.

\section{ACKNOWLEDGEMENTS}

This work was supported in part by Bristol-Myers Squibb Canada Inc. and GlaxoSmithKline Canada Inc.

\section{REFERENCES}

1. Cady RK, Wendt JK, Kirchner JR, et al. Treatment of acute migraine with subcutaneous sumatriptan. JAMA1991;265:2831-2835.

2. The Subcutaneous Sumatriptan International Study Group. Treatment of migraine attacks with sumatriptan. N Engl J Med 1991;325:316-321.

3. Rapoport AM, Ramadan NM, Adelman JU, et al. Optimizing the dose of zolmitriptan (Zomig, 311C90) for the acute treatment of migraine. A multicenter, double-blind, placebo-controlled dose range-finding study. Neurology 1997;49:1210-1218.

4. Teall J, Tuchman M, Cutler N, et al. Rizatriptan (MAXALT) for the acute treatment of migraine and migraine recurrence. A placebocontrolled, outpatient study. Headache 1998;38:281-287.

5. Solomon GD, Cady RK, Klapper JA, et al. Clinical efficacy and tolerability of $2.5 \mathrm{mg}$ zolmitriptan for the acute treatment of migraine. Neurology 1997;49:1219-1225.

6. Tfelt-Hansen P, Teall J, Rodrigues F, et al. Oral rizatriptan versus oral sumatriptan: a direct comparative study in the acute treatment of migraine. Headache 1998;38:748-755.

7. Solomon GD, Cady RK, Klapper JA, et al. Clinical efficacy and tolerability of $2.5 \mathrm{mg}$ zolmitriptan for the acute treatment of migraine. Neurology 1997;49:1219-1225.

8. Bomhof M, Paz J, Legg N et al and the Rizatriptan-Naratriptan Study Group. Comparison of rizatriptan $10 \mathrm{mg}$ vs naratriptan 2.5 $\mathrm{mg}$ in migraine. Eur Neurol 1999;42:173-179.

9. Diclofenac-K/Sumatriptan Migraine Study Group. Acute treatment of migraine attacks: efficacy and safety of a nonsteroidal antiinflammatory drug, diclofenac-potassium, in comparison to oral sumatriptan and placebo. Cephalalgia 1999;19:232-240.

10. Kramer MS, Matzura-Wolfe D, Plis A, et al. A placebo-controlled crossover study of rizatriptan in the treatment of multiple migraine attacks. Neurology 1998;51:773-781.

11. Pfaffenrath V, Cunin G, Sjonell G, Prendergast S. Efficacy and safety of sumatriptan tablets $(25 \mathrm{mg}, 50 \mathrm{mg}$ and $100 \mathrm{mg}$ ) in the acute treatment of migraine: defining the optimum doses of oral sumatriptan. Headache 1998;38:184-190.

12. Headache Classification Committee of the International Headache Society. Classification and diagnostic criteria for headache disorders, cranial neuralgias, and facial pain. Cephalalgia 1988;8(Suppl 7):1-96.

13. Sheftell FD, Weeks RE, Rapoport AM, et al. Subcutaneous sumatriptan in a clinical setting: the first 100 consecutive patients with acute migraine in a tertiary care center. Headache 1994;34:67-72.

14. Tfelt-Hansen P. Efficacy and adverse events of subcutaneous, oral and intranasal sumatriptan used for migraine treatment: a systematic review based on number needed to treat. Cephalalgia 1998;18(8):532-538.

15. Silberstein SD, Lipton RB, Sliwinski M. Classification of daily and 
non-daily headaches: Field trial of revised IHS criteria. Neurology 1996;47:871-875.

16. Mahew NT, Kailasam F, Meadors L, et al. Treatment of oral sumatriptan nonresponders with $5 \mathrm{mg}$ zolmitriptan and $10 \mathrm{mg}$ rizatriptan: a comparative open trial. Headache 1999;39:368 (Abst).

17. The Oral Sumatriptan Dose-Defining Study Group. Sumatriptan: an oral dose-defining study. Eur Neurol 1991;31(5):300-305.

18. Visser WH, Terwindt GM, Reines SA, et al. Rizatriptan vs sumatriptan in the acute treatment of migraine. Arch Neurol 1996;53:1132-1137.

19. Visser WH, de Vriend RHM, Jaspers NHWM, Ferrari MD. Sumatriptan in clinical practice: a two year review of 453 migraine patients. Neurology 1996;47:46-51.

20. Visser WH, Burggraaf J, Muller LM, et al. Pharmacokinetic and pharmacodynamic profiles of sumatriptan in migraine patients with headache recurrence or no response. Clin Pharmacol Ther 1996;60:452-460.

21. MaassenVanDenBrink A, Vergouwe MN, Ophoff RA, et al. 5-HT ${ }_{1 B}$ receptor polymorphism and clinical response to sumatriptan. Headache 1998;38:288-291.

22. Visser WH, de Vriend RHM, Jaspers MHWM, Ferrari MD. Sumatriptan - Nonresponders: A survey in 366 migraine patients.
Headache 1996;36:471-475.

23. Somerville BW. The role of estradiol withdrawal in the etiology of menstrual migraine. Neurology 1972;22:355-365.

24. Somerville BW. The role of progesterone in menstrual migraine. Neurology 1971;21:853-859.

25. Merikangas KR, Angst J, Isler H. Migraine and Psychopathology: Results of the Zurich Cohort Study of Young Adults. Arch Gen Psychiatry 1990;47:849-853.

26. Breaslau N, Merikangas K, Bowden CL. Comorbidity of migraine and major affective disorders. Neurology 1994;44(Suppl 7):S17S22.

27. Cleare AJ, Murray RM, Sherwood RA, O’Keane V. Abnormal 5-HT receptor function in major depression: a neuropharmacological challenge study using sumatriptan. Psychol Med 1998;28:295-300.

28. Robins LN, Helzer JE, Croughan J, Ratcliff KS. National Institute of Mental Health diagnostic interview schedule. Arch Gen Psychiatry 1981;38:381-389.

29. Liebert RM, Spiegler MD. Personality: Strategies and Issues, 7th Ed. Pacific Grove CA, USA, Brooks-Cole Publishing Co., 1994;10:191-217.

30. The Sixteen Personality Factors Questionnaire (5th Ed). Institute for Personality and Ability Testing, Champaign, Illinois, 1993. 